\title{
Expanding cardiac pseudotumor
}

\author{
Krishna Bhagwat, MCh, ${ }^{\mathrm{a}}$ Jane Hallam, MBBS, ${ }^{\text {a }}$ Gangahanumaiah Shivanand, $\mathrm{MCh},{ }^{\mathrm{a}}$ \\ Mathew Brooks, MD, ${ }^{\mathrm{b}}$ Victoria Atkinson, MD, FRACS, ${ }^{\mathrm{a}}$ and John Goldblatt, MD, FRACS, ${ }^{\mathrm{a}}$ Parkville, \\ Victoria, Australia
}

Cardiac calcified amorphous tumor (CAT) is a rare pseudoneoplastic mass composed of calcium deposits in a background of amorphous degenerating fibrin. Although the pathogenesis of this entity is not well understood CAT is a clinically important pseudoneoplasm because it often raises high suspicion for malignancy.

\section{CLINICAL SUMMARY}

A 75-year-old woman presented with episodic presyncope associated with palpitations. She was diabetic and hypertensive with a history of rheumatic fever with associated valvular dysfunction. Physical examination revealed an irregular pulse rate of 82 beats/min and no signs of left heart failure. On auscultation, a soft diastolic murmur was heard.

Biochemical investigation results were all within normal limits, including serum calcium, parathormone levels, and proteins $\mathrm{C}$ and $\mathrm{S}$. Electrocardiography confirmed atrial fibrillation and showed periods of sinus rhythm and firstdegree heart block. In-hospital telemetry demonstrated episodes of complete heart block rate that required permanent pacemaker.

Transthoracic and transesophageal echocardiography showed the presence of a large echogenic mass at the basal inferior wall and inferoposterior mitral annulus extending into both the interventricular and interatrial septae. The mass appeared encapsulated, intramyocardial, and extensive $(5.4 \times 4.2 \mathrm{~cm})$. The posterior mitral valve leaflet was clearly compressed by the mass, causing mild mitral stenosis and mild mitral regurgitation. Left ventricular function was preserved. Transthoracic echocardiography, performed 3 years previously to investigate a diastolic murmur, revealed a $2.5 \times 1.8-\mathrm{cm}$ calcific mass behind the posterior mitral valve leaflet. The patient was lost to follow-up.

Computed tomography (Figure 1) of the chest and cardiac magnetic resonance imaging confirmed the presence

\footnotetext{
From the Department of Cardiothoracic Surgery, ${ }^{\mathrm{a}}$ and Department of Cardiology, Royal Melbourne Hospital, Parkville, Victoria, Australia.

Disclosures: Authors have nothing to disclose with regard to commercial support.

Received for publication Dec 26, 2010; revisions received Jan 19, 2011; accepted for publication Feb 9, 2011; available ahead of print Mach 28, 2011.

Address for reprints: Krishna Bhagwat, MCh, CVTS, Department of Cardiothoracic Surgery, Royal Melbourne Hospital, Grattan Street, Parkville, VIC 3051, Australia (E-mail: krishnabhagwat@gmail.com).

J Thorac Cardiovasc Surg 2011;141:e41-2

$0022-5223 / \$ 36.00$

Copyright (c) 2011 by The American Association for Thoracic Surgery doi:10.1016/j.jtcvs.2011.02.008
}

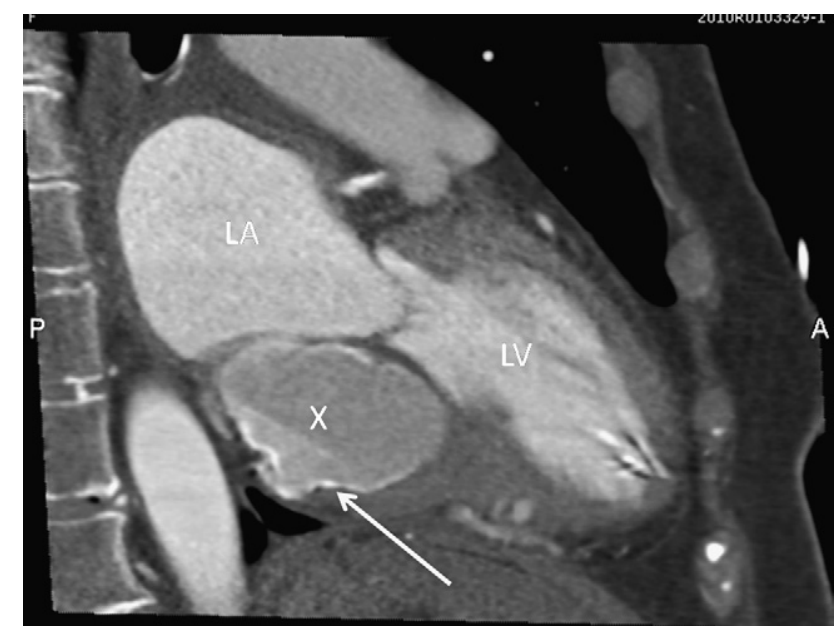

FIGURE 1. Computed tomography scans. Long-axis images show dense calcification attached to the left ventricular endocardium and mitral annulus. $L A$, Left atrium; $L V$, left ventricle; $A$, Anterior; $P$, posterior; $X$, calcific mass.

of a large, relatively dense intramyocardial mass $(56 \times 32 \times 42 \mathrm{~mm})$ arising in the vicinity of the posterior mitral annulus and enclosed within a fibrous capsule. Catheter coronary angiography revealed normal coronary arteries and calcified mass shadow.

The patient underwent cardiac exploration with a view to complete mass resection. Aorto-bicaval cardiopulmonary bypass was established, and a transseptal approach was adopted. On bimanual palpation, a firm intramyocardial mass was clearly felt, originating in the wall of the left atrium posterior to the posterior mitral annulus and extending across the mitral valve adjacent to the posteromedial commissure. The majority of the mass was in the inferior wall of the left ventricle with associated epicardial thickening and inflammation. An incision was made over the mass in the wall of the left atrium approximately $1 \mathrm{~cm}$ posterior to the mitral annulus, resulting in copious extrusion of chalky, gray-green toothpaste-like material. After evacuation of this material, the remaining cavity appeared to be lined by a thick capsule lined with fragmented calcification (Figure 2). With the use of a combination of 5-0 polypropylene interrupted sutures and a surgical glue set under bimanual compression, the cavity was minimized, if not obliterated.

Frozen-section examination of the left atrial wall and adjacent capsular tissue revealed calcific deposits, chronic inflammatory cells, and hemosiderin with reactive fibroblasts. There was no evidence of malignancy (Figure 3). 


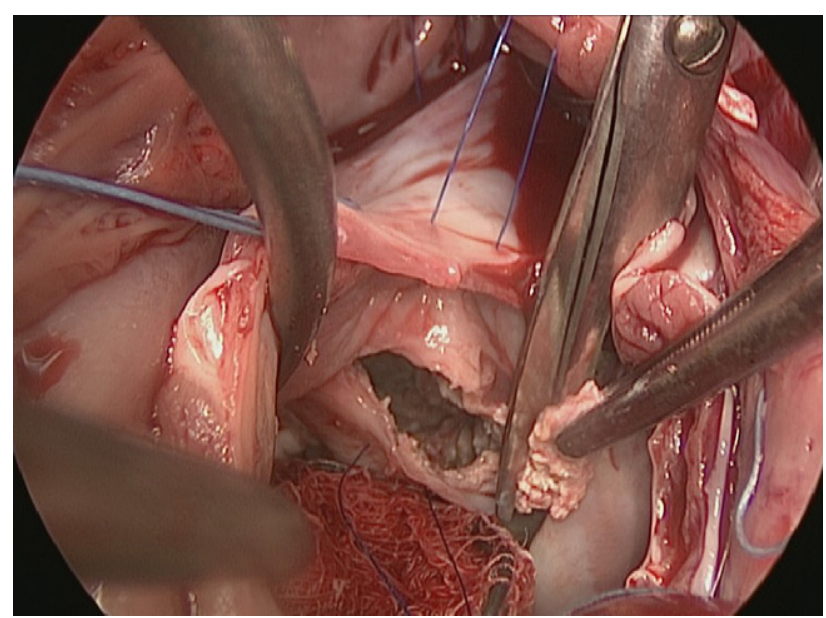

FIGURE 2. Intraoperative pictures show wall of the left atrium approximately $1 \mathrm{~cm}$ posterior to the mitral annulus.

Postoperative recovery was uncomplicated, and the patient was discharged on postoperative day 7 .

\section{DISCUSSION}

Primary cardiac masses may be neoplastic or nonneoplastic. Atrial myxomas are the most common type. The clinical manifestation of such masses usually stems from mechanical interference with cardiac function, the induction of arrhythmias, or their propensity to embolize.

The majority of cardiac tumors are non-neoplastic masses, such as thrombi, infective foci, or infestations. These can mimic neoplastic growths and cause difficulty in clinical diagnosis. A cardiac CAT is one such enigmatic mass. ${ }^{1,2}$

CAT is a rare tumor, with no such case reported from the Australasian subcontinent. The rarity of this tumor is seen by the fact that only 11 cases were reported over a 29year review at Mayo Clinic, where these primary cardiac pseudotumors were termed "CAT."1

CATs may occur in any chamber of the heart and consequently cause a variety of symptoms. The clinical presentation of CAT, however, is similar to many other cardiac masses, with shortness of breath, syncope, or arrhythmia. ${ }^{3}$ Our patient presented initially with murmur. The expanding nature of the mass caused more symptoms (dyspnea, presyncope, and palpitations), and the patient later went into complete heart block. Although the exact cause of CAT remains unclear, ${ }^{2}$ it may represent a degenerating intracavitary mural thrombus. ${ }^{4}$

Diagnosis is one of the most difficult aspects of CATs, with most cardiac imaging techniques unable to adequately characterize any pathognomonic features. Macroscopic examination of CAT usually consists of conglomerated

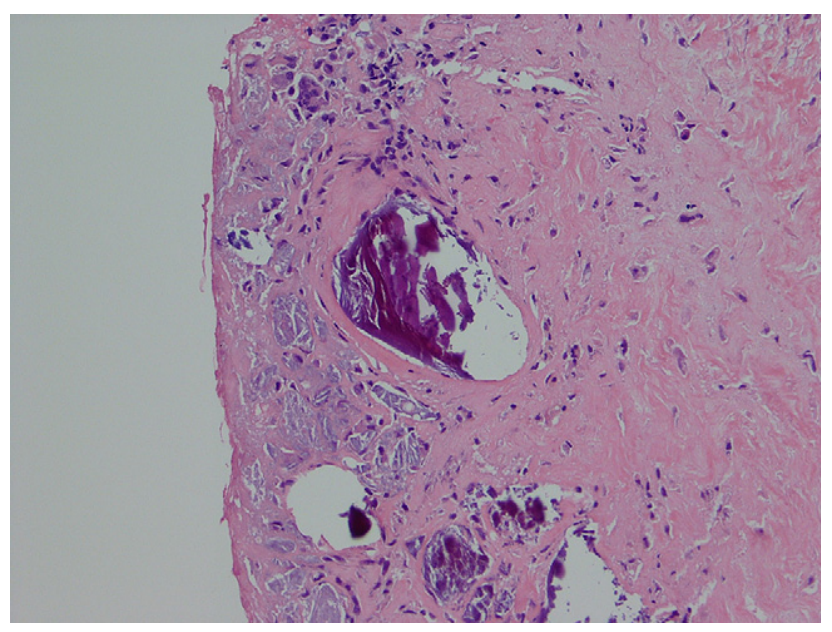

FIGURE 3. Histology shows calcific deposits, chronic inflammatory cells, and hemosiderin with reactive fibroblasts.

clot-like material, with chalky and focally mineralized calcification present at the center of the tumor. All CAT lesions have common histology and are predominantly composed of what appears to be degenerating fibrin with central nodular calcium deposits, mild to moderate chronic inflammation, and degenerating blood elements. ${ }^{5}$

Surgical removal of cardiac pseudotumors may be indicated for symptom relief or cardiac dysfunction, and excision should be curative; however, CAT lesions may recur in rare cases. ${ }^{2}$ Some large multifocal lesions may have a fatal outcome. ${ }^{6}$

\section{CONCLUSIONS}

Cardiac CATs remain a rare entity of unknown cause and are difficult to diagnose preoperatively. Surgical excision and histopathologic examination are mainstays of diagnosis.

\section{References}

1. Reynolds C, Tazelaar HD, Edwards WD. Calcified amorphous tumor of the heart (cardiac CAT). Hum Pathol. 1997;28:601-6.

2. Fealey ME, Edwards WD, Reynolds CA, Pellikka PA, Dearani JA. Recurrent cardiac calcific amorphous tumor: the CAT had a kitten. Cardiovasc Pathol. 2007;16: 115-8.

3. Habib A, Friedman PA, Cooper LT, Suleiman M, Asirvatham SJ. Cardiac calcified amorphous tumor in a patient presenting for ventricular tachycardia ablation: intracardiac echocardiogram diagnosis and management. J Interv Card Electrophysiol. 2010;29:175-8. Epub 2009 Jul 21.

4. Morishima A, Sasahashi N, Ueyama K. Calcified amorphous tumors with excision in hemodialysis patients: report of 2 cases. Kyobu Geka. 2006;59:851-4.

5. Miller DV, Tazelaar HD. Cardiovascular pseudoneoplasms. Arch Pathol Lab Med. 2010;134:362-8.

6. Lewin M, Nazarian S, Marine JE, Yuh DD, Argani P, Halushka MK. Fatal outcome of a calcified amorphous tumor of the heart (cardiac CAT). Cardiovasc Pathol. 2006;15:299-302. 